\title{
Sequential tumor and dual immune targeted immunotherapy: anti-lymphoma activity of Rituximab with 4-1bb stimulation and PD-1 blockade
}

\author{
Antonia MS Mueller ${ }^{1}$, Jonathan Hebb ${ }^{2}$, Idit Sagiv-Barfi ${ }^{2}$, Aurelien Marabelle ${ }^{3}$, Roch Houot ${ }^{4}$, Amanda Rajapaksa $^{2}$, \\ Debra K Czerwinski², Serena Chang ${ }^{2}$, Cariad Chester ${ }^{2}$, Mohith Sadaram², Erin Waller², Ronald Levy², \\ Holbrook Kohrt ${ }^{*}$
}

From Society for Immunotherapy of Cancer 29th Annual Meeting National Harbor, MD, USA. 6-9 November 2014

To select maximally-efficacious, minimally-toxic regimens of combination tumor- and immune-targeted therapy, preclinical testing in immune-competent models is required. We previously demonstrated 4-1bb(CD137) stimulation augmented the innate immune response mediated by CD137 ${ }^{+}$activated natural killers (NK) cells and the subsequent $\mathrm{CD}^{+} \mathrm{T}$ cell adaptive immune response when administered after tumor-targeting, ADCC-competent, mAbs targeting CD20, HER2, and EGFR. As four ongoing clinical trials (NCT01471210, NCT01775631, NCT02110082, NCT01307267) investigate this strategy, the $\mathrm{CD} 8^{+} \mathrm{T}$ cell response stimulated by 4-1bb was determined pre-clinically to be further augmented by PD-1/PD-L1 blockade, and a clinical trial is planned (NCT02179918). Taken together, we hypothesized, sequential tumor-targeting with anti-CD20 mAb, Rituximab, followed by dual immune-targeting with anti-CD137 agonism and PD-1/ PD-L1 blockade would be efficacious and tolerable due to non-overlapping immune mechanisms and toxicity profiles.

Preclinical modeling was performed in a therapeutic, syngenic, A20 lymphoma BALB/c model combining antiCD20 mAb (IgG2a-18B12, delivered intraperitoneally, i.p. on d5) with agonistic anti-CD137 mAb (IgG2a-2A, i.p. d6) and anti-PD-1 mAb (IgG2a-RMPI-14, i.p. d6) with intratumoral (i.t.) and circulating (c.) immune responses phenotyped by flow cytometry and time of flight mass cytometry (CyTOF). Combination immunotherapy with anti-CD137

${ }^{2}$ Stanford University, Stanford, CA, USA

Full list of author information is available at the end of the article and anti-PD1 was superior to either monotherapy without anti-CD20 treatment in a dose-dependent manner $(p<.001$ tumor-growth, $p<.001$ survival), though no mice were cured long-term. When administered following anti-CD20 treatment, combination immunotherapy with anti-CD137 and anti-PD1 was superior to either monotherapy in a sequence-dependent manner ( $p<.001$ tumor-growth, and $p<.001$ survival) with all mice cured long-term and protected from re-challenge when anti-CD20 preceded combination immunotherapy. Target expression was dynamic, as exemplified by highest CD137 expression on i.t.Tregs, followed by i.t.CD8 ${ }^{+} \mathrm{T}$ cells. Following anti-CD20 mAb treatment, 1) CD137 expression increased 5-10x on i.t. NKs and 2-6x increase on c.NKs; 2) PD-L1 expression increased on $\mathrm{A} 20$ tumor and i.t.CD8 ${ }^{+} \mathrm{T}$ cells, and minimally on i.t.NKs; and 3) PD-1 expression increased on i.t. Tregs, i.t.CD ${ }^{+} \mathrm{T}$ cells, and i.t.NKs. Treatment with antiCD137 agonist and PD-1 blockade 1) increased the ratio of i.t.NKs/Tregs and c.CD $8^{+} \mathrm{T}$ cells/Tregs, and 2) increased i.t. and c.CD ${ }^{+} \mathrm{T}$ cell tumor-specific IFN- $\gamma$ secretion and i.t. and c.NK cell degranulation. Laboratory and necropsy studies identified B cell lymphopenia and mild transaminitis which was notably marked with combination immunotherapy.

We conclude that sequential tumor-targeting followed by dual immune-targeting is highly-efficacious with predictable toxicity and should be considered for clinical translation to augment three therapies with only marginal activity as monotherapy in advanced, relapsed/ refractory lymphoma. 


\section{Authors' details}

${ }^{1}$ University Hospital Zurich, Zurich, Switzerland. ${ }^{2}$ Stanford University, Stanford, CA, USA. ${ }^{3}$ Centre de Recherche en Cancérologie de Lyon, Université de Lyon, Lyon, France. ${ }^{4}$ Service d'Hématologie Clinique, Centre Hospitalier Universitaire de Rennes, Rennes, France.

Published: 6 November 2014

doi:10.1186/2051-1426-2-S3-P106

Cite this article as: Mueller et al:: Sequential tumor and dual immune targeted immunotherapy: anti-lymphoma activity of Rituximab with 4-

$1 \mathrm{bb}$ stimulation and PD-1 blockade. Journal for ImmunoTherapy of Cancer 2014 2(Suppl 3):P106.

Submit your next manuscript to BioMed Central and take full advantage of:

- Convenient online submission

- Thorough peer review

- No space constraints or color figure charges

- Immediate publication on acceptance

- Inclusion in PubMed, CAS, Scopus and Google Scholar

- Research which is freely available for redistribution

Submit your manuscript at www.biomedcentral.com/submit 